\title{
Questionnaire Research and Development of Self-Motivating Education Method Using Intellectual Property Rights
}

\author{
http://dx.doi.org/10.3991/ijep.v2i4.2240 \\ Yoshihiro Deguchi ${ }^{1}$, Emi Morimoto ${ }^{1}$, Takehito Yoshida ${ }^{2}$, Akinobu Shimada $^{3}$, Naoko Akamatsu ${ }^{4}$, Hiroyuki \\ Maei $^{5}$, Nobuaki Shiokawa ${ }^{6}$, Hiroyuki Nakanishi ${ }^{7}$, Tsuneyoshi Kouda ${ }^{8}$ \\ ${ }^{1}$ The University of Tokushima, Tokushima, Japan, ${ }^{2}$ Anan National College of Technology, Tokushima, Japan \\ ${ }^{3}$ Tokushima Prefectural Senior High School of Science and Technology, Tokushima, Japan, ${ }^{4}$ Seiju IP firm, Osaka, \\ Japan \\ ${ }^{5}$ Kitahama International IP Law Firm, Osaka, Japan, ${ }^{6}$ Nitta Corporation, Osaka, Japan \\ ${ }^{7}$ Japan Tobacco Inc., Osaka, Japan, ${ }^{8}$ Tose Co., LTD, Osaka, Japan
}

\begin{abstract}
It may be no exaggeration to say that the intellectual contribution gains an important position in the Japanese economic strategy. In regard to the intellectual property, most of the attention focuses on creation and protection of intellectual property. However, education on intellectual properties is important as a long-term strategy to form a solid foundation of creative human resources. Especially, the active education is necessary to cultivate the student independent creativity. In this study the University of Tokushima, Anan National College Technology, and Tokushima Prefectural Senior High School Science and Technology have jointly taken action on the active education to enhance the creativity of students on intellectual properties. The patent and the design contests are utilized to cultivate the student creativity by having an experience of the invention processes. In this self-motivating education method patent attorneys brush up the student's idea through discussion in a small group to create inventions such as an electric bulb for an earthquake. According to the questionnaire research and student evaluation, this type of education covers both needs of industries and curiosities of students and leads to form a solid foundation of human resources of the future.
\end{abstract}

Index Terms-Interectual propery; Patent; Creativity; Selfmotivation

\section{INTRODUCTION}

The relative position of Japanese economy tends to decrease in the future. According to the world economy estimation in 2050 announced by Goldman Sachs Economic Research ${ }^{[1]}$, Japanese GDP becomes to rank 8th behind China, United States, India, Brazil, Mexico, Russia, and Indonesia. As for income per capita, Japan also ranks $8^{\text {th }}$, which means that Japan falls on the bottom of so-called "Rich Group". Because of these factors, it may be no exaggeration to say that the intellectual contribution gains an important position in the Japanese economic strategy. Recently, the significance of intellectual property is reaffirmed and the education based on intellectual property is reinforced in each grade. However, the passive education in which students learn the concept and mechanism of intellectual property is the mainstream curriculum and each organization has its curriculum independently. The active education with the cooperation of several organizations is necessary to form a solid foundation of creative human resources.

\section{PURPOSE OF SELF-MOTIVATING EDUCATION}

Education of intellectual property has been diversified and many approaches have been employed in each organization $^{[2]}$. In the case of universities, however, the main intellectual output is research papers and university teachers have little interest in intellectual properties such as patents. This has been reflected in the education aspect. It is general for engineering students who are assigned to a laboratory to write research papers, but it is rare for them to apply for patents. On the one hand, companies give priority to patents compared to research papers. Because most of the graduates get into companies, it is necessary boost the awareness of intellectual property in university education.

The survey among engineering undergraduate and graduate students in the University of Tokushima has been conducted to find out the perception of patents and research papers from the student's point of view. The results are shown in TABLE I. Total quantity of responses was 245 by undergraduates and graduate students. Many students think patents are difficult to apply for compared to research papers. However they have an image that patents are attractive and they wants to embody their own idea as a patent. Figure 1 shows the questionnaire results about the perception of patents and research papers from the student's point of view. Total quantity of responses was 111 , which consists mainly of companies in the manufacturing. Most of the companies require the enhancement of creativity on intellectual properties for university students because it is the key factor of company's sustainable growth. It is worth nothing that the industrial arena places priority on the creativity of intellectual properties for new employees (engineering work, new graduates) compared to the ability to write papers and reports. According to these results, selfmotivating education using intellectual property, in which students can learn the process how to embody their ideas as intellectual properties, satisfies both company needs and student's interests. 
TABLE I.

PERCEPTION OF PATENTS AND RESEARCH PAPERS FROM THE STUDENT'S POINT OF VIEW

\begin{tabular}{|c|c|c|}
\hline \multirow{2}{*}{ Question } & \multicolumn{2}{|c|}{ Percentage of responses (\%) } \\
\cline { 2 - 3 } & Patent & $\begin{array}{c}\text { Research } \\
\text { paper }\end{array}$ \\
\hline \hline $\begin{array}{c}\text { Which is more difficult to } \\
\text { understand? }\end{array}$ & 69 & 24 \\
\hline Which is more attractive to learn? & 67 & 24 \\
\hline What kind of image do you have? & $\begin{array}{c}\text { Monetary: } \\
58\end{array}$ & $\begin{array}{c}\text { Academic: } \\
84\end{array}$ \\
\hline $\begin{array}{c}\text { Which is more attractive to be an } \\
\text { author (or inventor)? }\end{array}$ & 48 & 35 \\
\hline $\begin{array}{c}\text { What kind of patent do you want to } \\
\text { apply for? }\end{array}$ & $\begin{array}{c}\text { - based on student's own } \\
\text { idea: } 59 \% \\
\text { based on research in } \\
\text { university: } 32 \%\end{array}$ \\
\hline
\end{tabular}

Total quantity of responses: 245 students

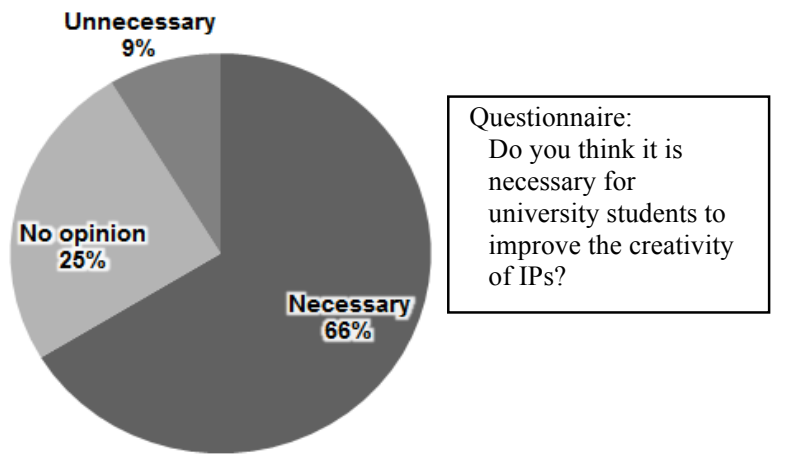

(a) Necessity of creativity on IPs

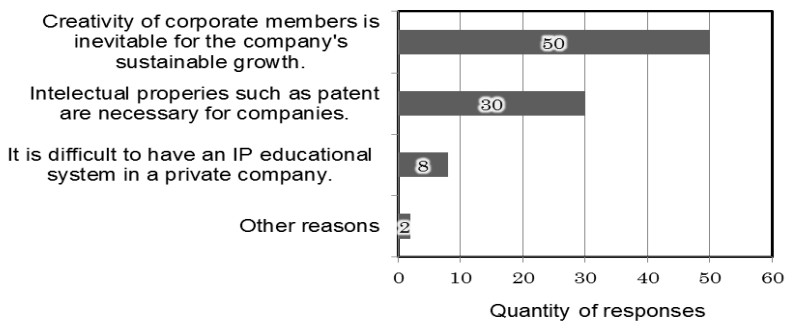

(b) Reason of the necessity of creativity on IPs

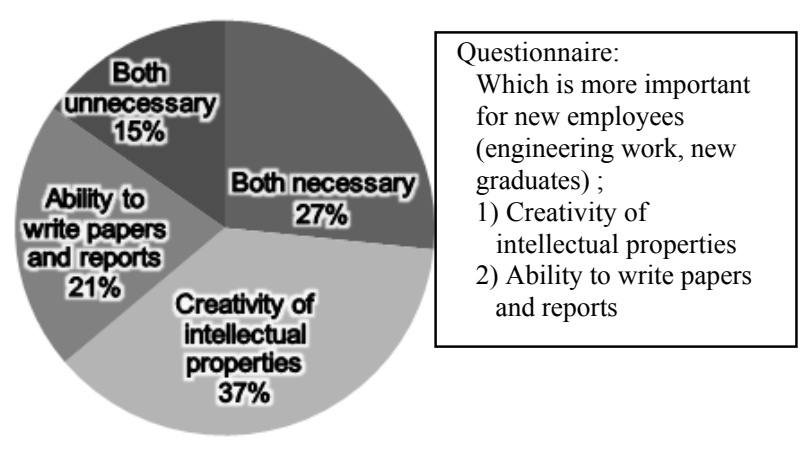

(c) Required capability

Figure 1. Questionnaire results of companies about questionnaire results about the perception of patents and research papers from the student's point of view

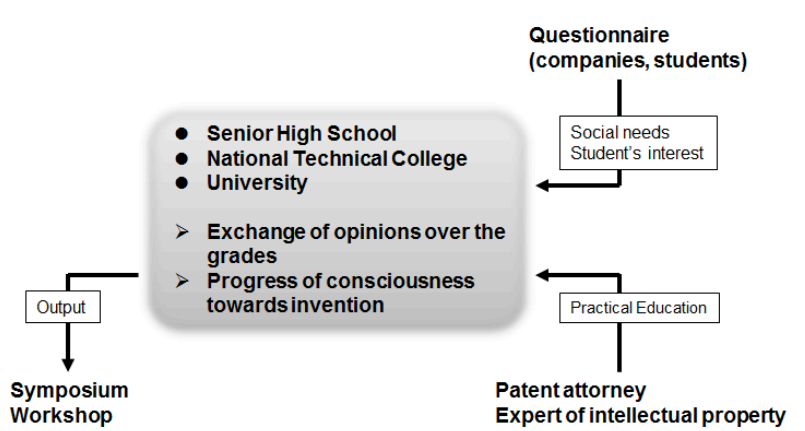

Figure 2. Framework of this educational research project

\section{PRACTICE OF SELF-MOTIVATING EDUCATION}

The joint education project has been conducted with the cooperation of university, National Technical College, senior high school as a part of social action work in the University of Tokushima. The framework of this project is shown in Figure 2. In this project, a forum for discussion has been set up between students and patent attorneys for the purpose of raising the student's awareness about intellectual properties.

\section{A. Practice in the University of Tokushima}

The role of intellectual property in universities has been of growing importance in many fields. These fields include intellectual properties created by university researchers, education, academic-industrial alliances and so on. As mentioned above, universities have limited interest in intellectual properties compared to companies. On the other hand, intellectual properties have been considered to be the company's lifeblood in the industry. On the basis of this point, the self-motivating education curriculum using intellectual property rights has been conducted in the University of Tokushima ${ }^{[3]}$. In this education, students can learn and practice the creation process of intellectual properties.

TABLE II shows the IP education curriculums in the University of Tokushima. The practice of self-motivating education has been demonstrated in the Seminar on Creation of Intellectual Property. In order for students to experience the excavation and cultivation process of invention, patent attorneys handle small classes and experience this process with each student. As a means of this education, the Patent and Design-patent Contests ${ }^{[4]}$ are employed to embody the student's ideas and designs. The Ministry of Education, Culture, Sports, Science and Technology, the Japan Patent Office, the Japan Patent Agency Association, and the National Center for Industrial Property Information and Training jointly holds these contests every year since 2003 (Design-patent Contest: since 2009) and award winners can apply for their ideas and designs with the support of organizers. Generally a target of research papers is "a discovery of new truth", on the other hand that of invention is "a creation of technical ideas utilizing natural laws". The invention intrinsically contains concrete contents and students tend to grasp the essence of invention rather easily.

Figure 3 shows pictures of the Seminar on Creation of Intellectual Property. In this class there were 6 lectures, all of who were patent attorneys, and each lecturer was in charge of 4-5 students. It is worth mentioning that each 
student has his or her won task and experiences the different excavation and cultivation process with each other.

TABLE III shows the questionnaire result about the comparison between this self-motivating curriculum and other classes. Because this curricurum employed participatory approach and students created their own task, they rated this curricurum superior to other clases about all the items (interest, concentration, creation of one's own idea, and cooperation with lecturers). Figure 4 shows the student evaluation result about the common questions for all classes in the engineering department of the Universiyu of Tokushima. The Seminar on Creation of Intellectual Property shows better evaluation result in almost all the question items. Three students who took the course were awarded in the 2011 Patent Contest.

\section{B. Regional cooperation}

This education project has been conducted with the cooperation of the University of Tokushima, Anan National College of Technology, and Tokushima Prefectural Senior High School of Science and Technology. The discussion between students and patent attorneys has been conducted in each school. Figure 5 (a) and (b) shows photographs of discussion processes conducted in Anan National College of Technology and Tokushima Prefectural Senior High School of Science and Technology, respectively. Student's creativity can be greatly diversified through discussions with patent attorneys. The idea note for three schools has been designed and delivered to students in three schools. It was designed in Tokushima Prefectural Senior High School of Science and Technology and has been used to support the student's creativity. Six students who took the course were awarded in the 2011 Patent and Design-patent Contests.

\section{CHALLENGE AND FUTURE WORK}

When intellectual property education is considered, especially from the viewpoint of promoting opportunities for students to be involved in inventions, the final target can be the total procedure of applying for the patent and acquiring the intellectual property right through the patent examination. In this respect, the Patent Contest mentioned above has an advantage for students. However, there are several problems to further promote this type of education. One of them is the cost of patent application of ideas created by students. The cost of patent application is not recognized as an educational expense. TABLE IV shows the comparison about the support system of student patent applications between Japan and Korea ${ }^{[5]}$. Korea employs better support systems in this respect because major fees of student applications are exempted. The system in which more students can learn and experience the creation of invention seems to be necessary in Japan.

It is also important for students to venture into the real industrial problems in terms of ideas and designs. In this respect regional cooperation with companies is an effective and efficient measure and this type of cooperation is in progress by the social action work of the University of Tokushima.
TABLE II.

IP EDUCATION CURICURUM IN THE UNIVERSITY OF TOKUSHIMA

\begin{tabular}{|c|c|}
\hline Curriculum name & Contents \\
\hline $\begin{array}{l}\text { Basics and } \\
\text { Applications of } \\
\text { Intellectual Property } \\
\text { (16 units: } 24 \text { hours) }\end{array}$ & $\begin{array}{l}\text { - System of intellectual property rights } \\
\text { - Patent property and infringement } \\
\text { - Patent specification } \\
\text { - Know-how on intellectual property for } \\
\text { engineers } \\
\text { - Applications of intellectual property }\end{array}$ \\
\hline $\begin{array}{l}\text { Seminar on Creation } \\
\text { of Intellectual } \\
\text { Property } \\
\text { (16 units: } 24 \text { hours) }\end{array}$ & $\begin{array}{l}\text { - }[\text { Practice of self-motivating education] } \\
\text { - Evacuation of idea } \\
\text { - Patent survey } \\
\text { - Evaluation of novelty and inventiveness } \\
\text { - Cultivation of invention through group } \\
\text { discussion } \\
\text { - Report and presentation } \\
\text { - Application to patent contest }\end{array}$ \\
\hline
\end{tabular}

TABLE III. COMPARISON BETWEEN THIS SELF-MOTIVATING CURRICURUM AND OTHER CLASSES

\begin{tabular}{|c|c|c|c|}
\hline \multirow{2}{*}{ Question } & \multicolumn{3}{|c|}{ Comparison with other classes (\%) } \\
\hline & Superior & Equal & Inferior \\
\hline Interest & 82 & 18 & 0 \\
\hline Concentration & 73 & 27 & 0 \\
\hline $\begin{array}{l}\text { Creation of one's } \\
\text { own idea }\end{array}$ & 91 & 9 & 0 \\
\hline $\begin{array}{l}\text { Cooperation with } \\
\text { lecturers }\end{array}$ & 100 & 0 & 0 \\
\hline
\end{tabular}

Total quantity of responses: 11 students

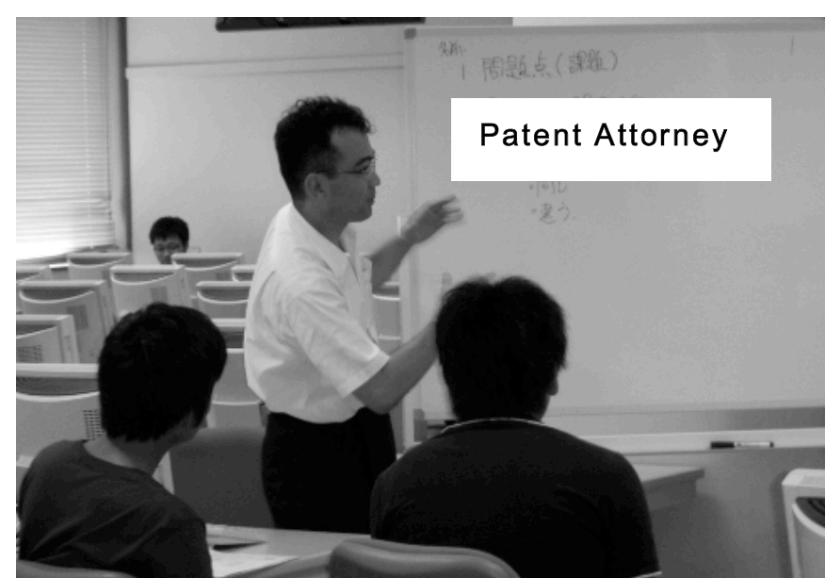

(a) Lecture of invention process

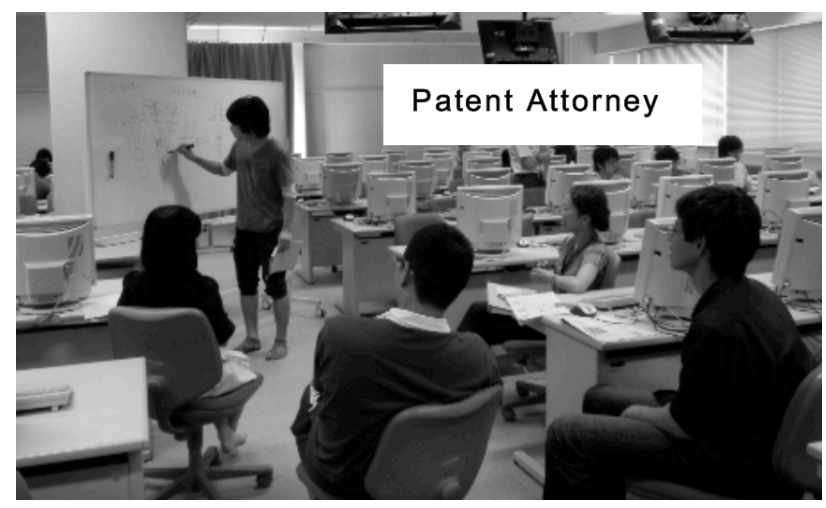

(b) Excavation and cultivation meeting

Figure 3. Pictures of seminar on creation of intellectual property 


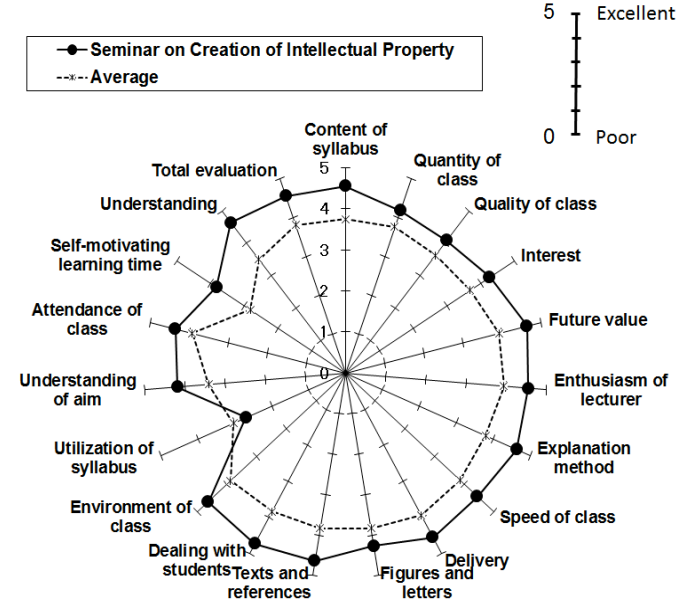

Figure 4. Student evaluation of Seminar on Creation of Intellectual Property

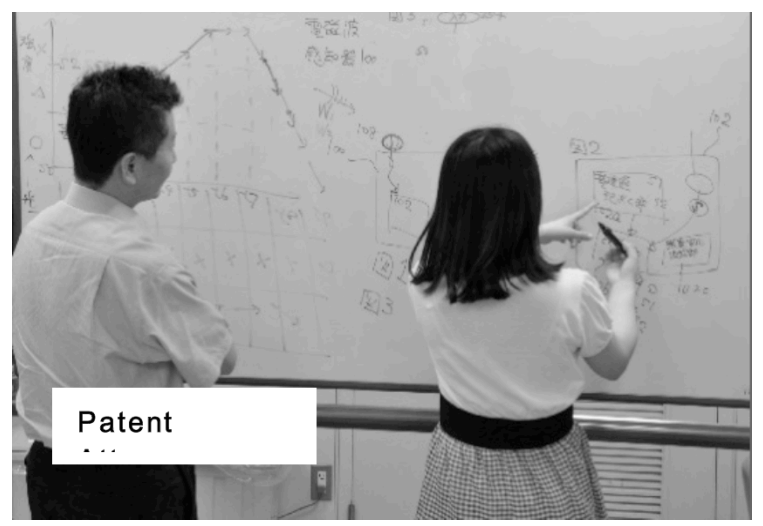

(a) Anan National College of Technology

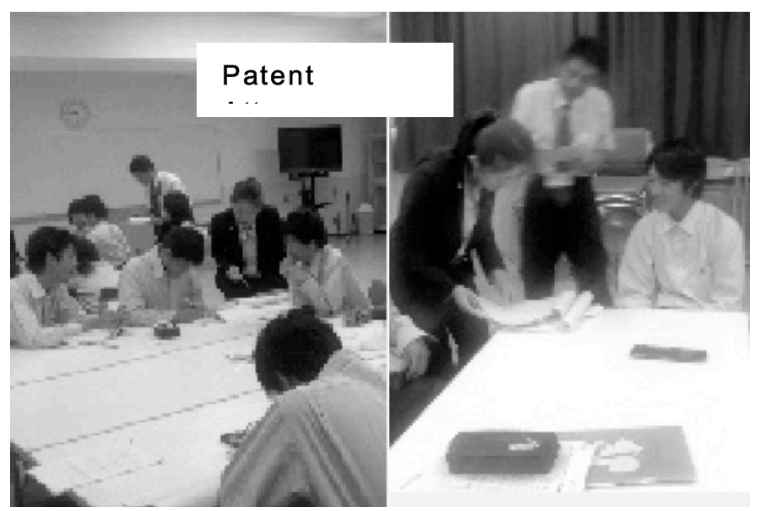

(b) Tokushima Prefectural Senior High School of Science and Technology

Figure 5. Pictures of seminars conducted in Anan National College of Technology and Tokushima Prefectural Senior High School of Science and Technology

TABLE IV. COMPARISON ABOUT SUPPORT SYSTEM OF STUDENT PATENT APPLICATION BETWEEN JAPAN AND KOREA

\begin{tabular}{|l|l|l|}
\hline \multicolumn{1}{|c|}{ Items } & \multicolumn{1}{c|}{ Japan } & \multicolumn{1}{c|}{ Korea } \\
\hline \hline Application fee & Necessary(15,000yen) & Exemption(Free) \\
\hline $\begin{array}{l}\text { Examination request } \\
\text { fee }\end{array}$ & Reduction or Exemption & Exemption (Free) \\
\hline $\begin{array}{l}\text { Patent fee (1 3 } \\
\text { years) }\end{array}$ & Reduction or Exemption & Exemption (Free) \\
\hline Patent attorney fee & Necessary & Free support by KPAA \\
\hline
\end{tabular}

KPAA: Korea Patent Attorneys Association

\section{CONCLUSIONS}

The Questionnaire research and practice of selfmotivating education have been demonstrated in three educational institutions. The major results obtained in this research are shown below.

1. Self-motivating education using intellectual property right where students create their own inventions complies with both company needs and student's interests.

2. Regional cooperation of self-motivating education using intellectual property right tends to induce synergistic effects to enhance the student's creativity.

\section{REFERENCES}

[1] "The N-11: More Than an Acronym", Global Economic Paper No.153, Goldman Sachs Economic Research, March 28, 2007.

[2] H. Arai, "Japan's intellectual property strategy", World Patent Inform, 28, 4, pp. 323-326, 2006. http://dx.doi.org/10.1016/ j.wpi.2006.07.006

[3] Y. Deguchi, T. Yoshida, A. Shimada, N.Akamatsu, and H. Maei, "Development of self-motivating education method using intellectual property rights", $2^{\text {nd }}$ Asian Conference on Engineering Education, October, 7-9, 2011, TS5-4:1-5..

[4] http://www.inpit.go.jp/jinzai/contest/

[5] J.H. Shim and Y. Deguchi, " Conjoint Comparison of Support Systems for Intellectual Property Activities of University Students in Science and Engineering Majors in Korea and Japan ", IEEE International Conference on Teaching, Assessment and Learning for Engineering 2012, submitted.

\section{AUTHORS}

Yoshihiro Deguchi and Emi Morimoto are with Graduate school of Advanced Technology and Science, The University of Tokushima, Tokushima, Japan, e-mail: ydeguchi@tokushima-u.ac.jp

Takehito Yoshida is with Department of Mechanical Engineering, Anan National College of Technology, Tokushima, Japan, e-mail: takehito@anan-nct.ac.jp.

Akinobu Shimada is with Tokushima Prefectural Senior High School of Science and Technology, Tokushima, Japan, e-mail: shimada-akinobu1@mt.tokushima-ec.ed.jp.

Naoko Akamatsu is with Seiju IP firm, Osaka, Japan, e-mail: naoko.akamatsu@seijuip.jp.

Hiroyuki Maei is with Kitahama International IP Law Firm, Osaka, Japan, e-mail: maei@kitahamaip.com.

Nobuaki Shiokawa is with Nitta Corporation, Osaka, Japan, e-mail: no_shiokawa@nitta.co.jp.

Hiroyuki Nakanishi is with Japan Tobacco Inc., Osaka, Japan, e-mail: hiroyuki.nakanishi@jt.com.

Tsuneyoshi Kouda is with Tose Co., LTD, Osaka, Japan, e-mail: t_koda@tose.co.jp.

This article is an extended version of a paper presented at IEEE International Conference on Teaching, Assessment and Learning for Engineering 2012 (TALE2012), held 20-23 August 2012, at The Hong Kong Polytechnic University, Hong Kong. Received 6 September 2012. Published as resubmitted by the authors 5 October 2012. 